7. Reprod. Fert. (1973) 33, 315-318

\title{
EMBRYONIC MORTALITY IN THE POST-PARTURIENT DOMESTIC RABBIT
}

\author{
G. R. FOXCROFT* AND H. HASNAIN $\dagger$ \\ Department of Physiology and Environmental Studies, \\ University of Nottingham School of Agriculture, \\ Sutton Bonington, Loughborough, Leicestershire
}

(Received 29th August 1972)

Embryonic mortality in domestic rabbits ovulating in response to post-partum matings was investigated initially by Hammond (1925). In non-suckling does or does with small litters, pregnancies were successfully established soon after parturition and mortality appeared to be at a normal level. In does suckling larger litters, however, there was a high incidence of embryonic mortality especially in the early postimplantation period and this was associated with luteal regression. The elevated mortality may have resulted from an inadequate plane of nutrition resulting in reduced FSH secretion and follicular development, associated with luteal regression and absorption of embryos (Adams, 1967). The fertility of post-partum matings has been more recently investigated in Dutch Belted (DB) and Large Albino (LA) strains of rabbits (Foxcroft \& Hasnain, 1973) and the levels of embryonic mortality in does mated during the early period after parturition are reported in this communication.

Does were allocated to experimental groupings after kindling normally at the end of their first (DB does) and second (LA does) pregnancies. The conditions of management and housing were as reported previously (Foxcroft \& Hasnain, 1973). The litters of DB does were standardized to five young/doe on the day of parturition (Day 0) and the does were tested for mating with fertile males on Days 3, 6, 9 and 12 post partum with a control group mated after weaning on Day 21. The LA does were either suckling (six young/doe) or non-suckling (young removed at birth) and were tested for mating on Days 3, 6, 9 and 12 post partum.

In the previous study using LA does and the same experimental groupings (Foxcroft \& Hasnain, 1973), the development of ova was observed after recovery 2 days post coitum and data on the estimated abnormal development of ova in does that ovulated are included in the present communication. In the present study, does were examined either at autopsy or at laparotomy 9 days post coitum and the numbers of corpora lutea and implantation sites were recorded.

The estimates of early abnormal development in LA does are shown in Table 1. No total loss of embryos was observed 2 days post coitum in these does. Comparison between suckling and non-suckling does at each time of mating

\footnotetext{
* Present address: Department of Animal Science, Animal Genetics Laboratory, University of Illinois, Urbana, Illinois 61801 , U.S.A.

$\dagger$ Present address: West Pakistan Veterinary Research Institute, Harike Road, Lahore, Cantt-13, Pakistan.
} 
and an overall comparison of all suckling and non-suckling does failed to reveal any significant effects of suckling on the early development of ova; the mean percentage of abnormal ova was estimated as 19.0 and 16.8 for the suckling and non-suckling does, respectively. Despite this lack of significance, the effects of time of mating tended to produce different patterns of abnormal development. In suckling does, $\chi^{2}$ analysis showed that abnormal development was significantly greater in animals mated on Day 3 than on Days 9 and $12(P<0.01$ and 0.05 , respectively) and that significantly less abnormal development was present after mating on Day 9 than after Day $6(P<0.05)$. In non-suckling does by comparison, abnormal development was minimal after Day-12 matings and was significantly below that observed after matings on Days 3 and 6 post partum $(P<0.01$ and 0.05 , respectively).

Table 1. Early embryonic mortality estimated 2 days post coitum in Large Albino does mated in the early post-partum period

\begin{tabular}{c|c|c|c|c|c|cr}
\hline Group & $\begin{array}{c}\text { Total no. } \\
\text { of corpora } \\
\text { lutea }\end{array}$ & $\begin{array}{c}\text { No. of ova } \\
\text { observed }\end{array}$ & $\begin{array}{c}\% \\
\text { recovery }\end{array}$ & $\begin{array}{c}\% \\
\text { fertilized }\end{array}$ & $\begin{array}{c}\text { No. of } \\
\text { abnormal } \\
\text { ova }\end{array}$ & $\begin{array}{c}\text { Embryonic } \\
\text { mortality } \\
A^{*}\end{array}$ \\
\hline Suckling & & & & & & & \\
3 & 46 & 43 & 93 & 98 & 12 & 28 & 33 \\
6 & 73 & 73 & 100 & 84 & 18 & 25 & 25 \\
9 & 36 & 35 & 97 & 100 & 1 & 3 & 6 \\
12 & 82 & 79 & 96 & 98 & 8 & 10 & 13 \\
Non-suckling & 76 & 64 & 84 & 93 & 8 & 13 & 26 \\
3 & 75 & 71 & 95 & 100 & 11 & 15 & 20 \\
6 & 68 & 68 & 100 & 100 & 10 & 15 & 15 \\
9 & 79 & 79 & 100 & 100 & 5 & 6 & 6 \\
12 & & & & & & & \\
\hline
\end{tabular}

* A-Abnormal and unfertilized ova expressed as a percentage of all ova recovered.

$\dagger \mathrm{B}-\mathrm{Abnormal}$, unfertilized and unrecovered ova as a percentage of total CL observed.

The preimplantation mortality estimated 9 days post coitum is shown in Table 2. Only data for does that were observed with implants are shown for DB females, whereas the data for LA does show instances of total loss of ova between ovulation and implantation. Total loss of ova in all LA does accounted for $21.2 \%$ of the initial ovulations and appears to be a greater cause of embryonic wastage than that observed in normally mated rabbits (Adams, 1960).

Exclusive of total loss, the estimates of preimplantation mortality revealed no significant effects of time of mating, with the exception of the DB does, in which the mortality in the does mated after weaning on Day 21 post partum was significantly greater than that in does mated on Days 6 and $9(P<0.001$ and $0 \cdot 01$, respectively).

In the LA does, there was considerably less embryonic mortality in the suckling than in the non-suckling animals, the mean mortalities accounting for 9.0 and $15.7 \%$ of the initial ovulations in the suckling and non-suckling groups. The lowest levels of mortality in suckling does were observed after mating on Days 6 and 9 post partum in both the DB and LA strains (see Table 2) and the data for the LA does mated 9 days after parturition showed that mortality was significantly greater in the non-suckling animals $(P<0.01)$. 


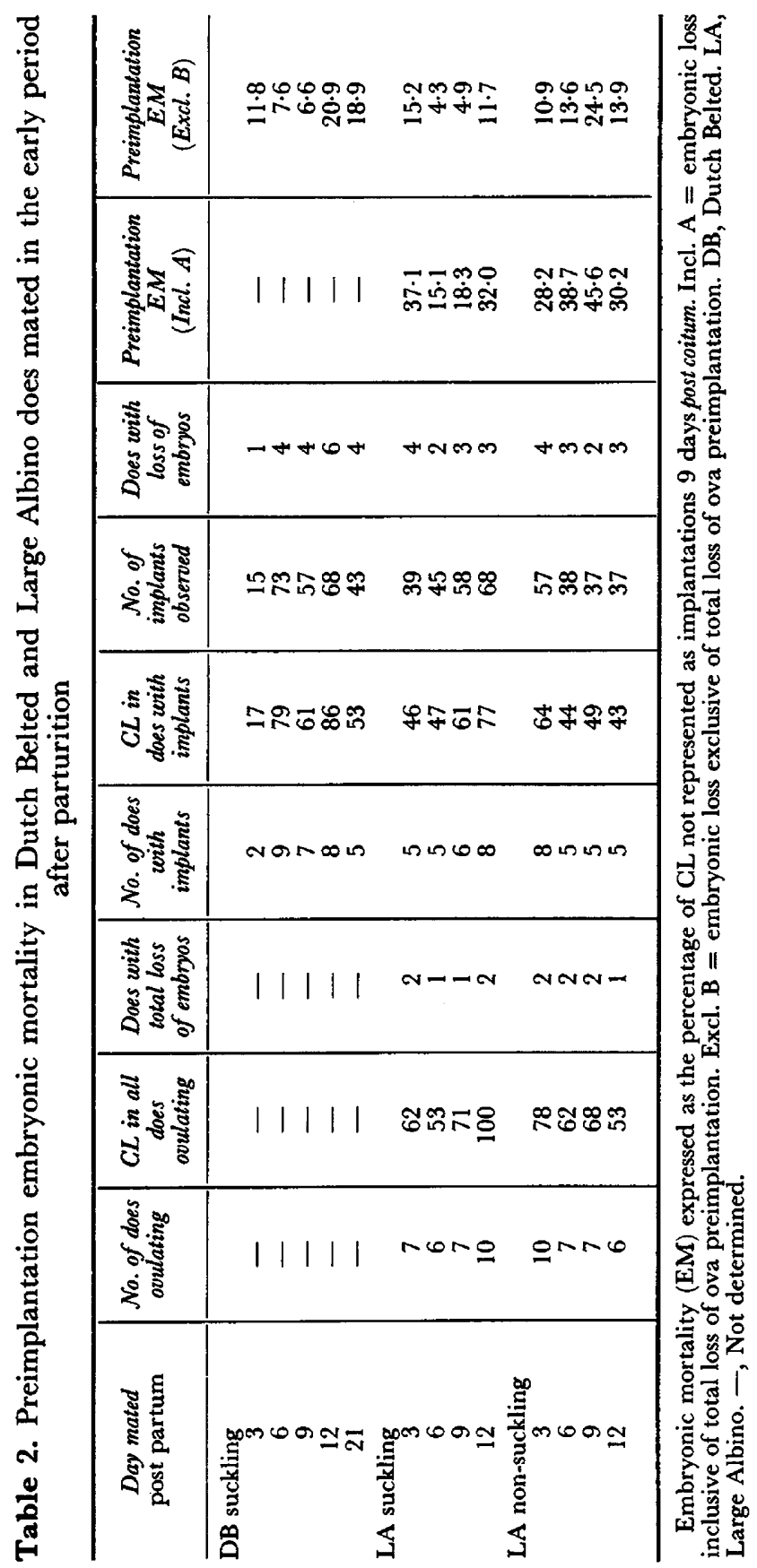


Although further investigations are necessary with larger numbers of animals to establish the significance of time of mating and suckling on embryonic mortality in the post-partum rabbit, some interesting points arise. When estimated 9 days post coitum, the level of preimplantation mortality appeared to be considerably greater in non-suckling does mated soon after parturition. The beneficial effects of suckling in reducing embryonic mortality were observed only in those females mated on Day 6 and Day 9, and a previous study on the morphology of the ovary and uterus in the post-partum animal (Foxcroft \& Hasnain, 1973) suggested that enhanced uterine involution in suckling females may be associated with these reductions in embryonic loss. At the same time, however, the pattern of abnormal development estimated in ova 2 days post coitum suggested that similar effects of suckling may have been present in does mated on Day 9 post partum, when ova were within the tubal environment, and the suckling stimulus may therefore produce a more extensive effect on early embryonic development.

Adams (1960) reported a $9.7 \%$ embryonic mortality in normally mated does in the preimplantation period, exclusive of total loss. This suggests that mortality during the same period of gestation in rabbits mated post partum is generally at a higher level but that mating at certain optimal times (i.e. Days 6 and 9 post partum) may result in a decrease in embryonic loss in suckling animals.

Although extensive investigations on postimplantation embryonic mortality have not been possible in the present studies, initial results from LA does have demonstrated considerably elevated postimplantation loss in does mated on Days 3 to 12 post partum ( $26 \cdot 8 \%$ of initial ovulations, exclusive of total loss) compared to normally mated females (see Adams, 1960). In addition, suckling appeared to have a converse effect on postimplantation mortality to that observed for the earlier period of gestation, and produced a higher level of embryonic loss $(30.4 \%)$ than was observed in the non-suckling animals $(23.9 \%)$.

As a result of these contrasting effects of suckling on embryonic loss at different stages of gestation, the total prenatal loss of embryos following matings post partum appears to be similar in both suckling and non-suckling rabbits and considerably greater than in animals that were not mated post partum.

We wish to acknowledge financial support from the Ministry of Agriculture, Fisheries and Food (G.R.F.) and from the British Council (H.H.) received during the course of this work.

\section{REFERENCES}

Adams, C. E. (1960) Studics on prenatal mortality in the rabbit, Oryctolagus cuniculus: the amount and distribution of loss before and after implantation. 7. Endocr. 19, 325.

Adams, C. E. (1967) Concurrent lactation and pregnancy in the rabbit. 7. Reprod. Fert. 14, 351.

Foxcroft, G. R. \& Hasnain, H. (1973) Effects of suckling and time to mating after parturition on reproduction in the domestic rabbit. 7 . Reprod. Fert. 33, 367.

Hammond, J. (1925) Reproduction in the rabbit. Oliver \& Boyd, London. 